\title{
Pericarditis or myocarditis: still a clinical problem
}

\author{
Jan W. Pęksa ${ }^{1}$, Anna Malinowska-Karpiel ${ }^{2}$, Marek Klocek ${ }^{1}$, Marek Rajzer ${ }^{1}$ \\ ${ }^{1}$ Department of Cardiology, Interventional Electrocardiology and Hypertension, Jagiellonian University \\ Medical College, Kraków, Poland \\ ${ }^{2}$ Department of Internal Medicine with the Sub-unit of Cardiology and the Sub-unit of Geriatrics \\ of the Independent Public Complex of Health Care in Brzesko, Poland
}

\begin{abstract}
Pericarditis and myocarditis are diseases of a similar etiology and clinical image, and they often overlap. Depending on the clinical manifestation, there is pericarditis with simultaneous involvement of the heart muscle (myopericarditis), or myocarditis with pericardial involvement (perimyocarditis). The paper presents a case of a young patient with myopericarditis, with attention to the electrocardiographic image and parameters of myocardial damage.
\end{abstract}

Key words: myopericarditis, troponins, electrocardiogram

Folia Cardiologica 2021; 16, 1: 55-58

\section{Introduction}

The pericardium, a loose-fitting structure surrounding the heart, consists of two layers, i.e. an inner layer - serous one (epicardium), which adheres to the cardiac muscle, and an outer layer - fibrous. Physiologically, between these layers there is friction-reducing fluid (10-50 mL). The most common, especially among young adults, disorder of pericardium is acute pericarditis. For the diagnosis of pericarditis, at least 2 of 4 criteria must be met: 1) pericardial chest pain, 2) pericardial friction rub, 3) characteristic changes in the normal electrocardiogram (ECG) pattern (newly detected ST elevations or PR depressions in multiple leads, in an acute phase of the disease), 4) presence of increased pericardial sac fluid found on echocardiography $[1,2]$.

Myopericarditis means pericarditis with a certain degree of coexistent myocarditis. Due to similar etiology of pericarditis and myocarditis, as well as anatomical proximity, overlapping of clinical pictures for both diseases is frequently observed in daily practice. The diagnosis of myopericarditis concerns the situation in which the symptoms of acute pericarditis predominate and there is also an increase in the levels of cardiomyocyte injury markers, but with no signs of fresh focal or diffuse left ventricular dysfunction. To make a diagnosis of perimyocarditis, on the other hand, it is necessary to find the above-mentioned abnormalities on echocardiography or magnetic resonance imaging in a patient who also meets the criteria for the diagnosis of acute pericarditis [1, 2].

\section{Case study}

A 21-year-old man - previously healthy - with suspected pericarditis was referred in February 2020 to the Department of Cardiology, Interventional Electrocardiology and Hypertension of the University Hospital in Krakow from the emergency department for further diagnosis and treatment. The reported symptoms included crushing chest pain lasting from about three weeks - initially right side pain, then (from about a week) left side pain, radiating to the left subscapular region. The pain occurred periodically, slightly intensified during inspiration and changing a body position (up to 6/10 points in Numeric Rating Scale [NRS]). Slight dyspnea occurred during physical effort. Furthermore, three weeks earlier, the patient reported an infection of the upper respiratory tract with severe symptoms such as sore throat, coughing, hoarseness and fever. The infection was not treated pharmacologically, and its symptoms almost disappeared.

Address for correspondence: Jan W. Pęksa MD, Klinika Kardiologii i Elektrokardiologii Interwencyjnej oraz Nadciśnienia Tętniczego, Szpital Uniwersytecki w Krakowie, ul. M. Jakubowskiego 2, 30-688 Kraków, Poland, phone +48 1240021 61, fax +48 1240021 67, e-mail: janwpeksa@gmail.com 

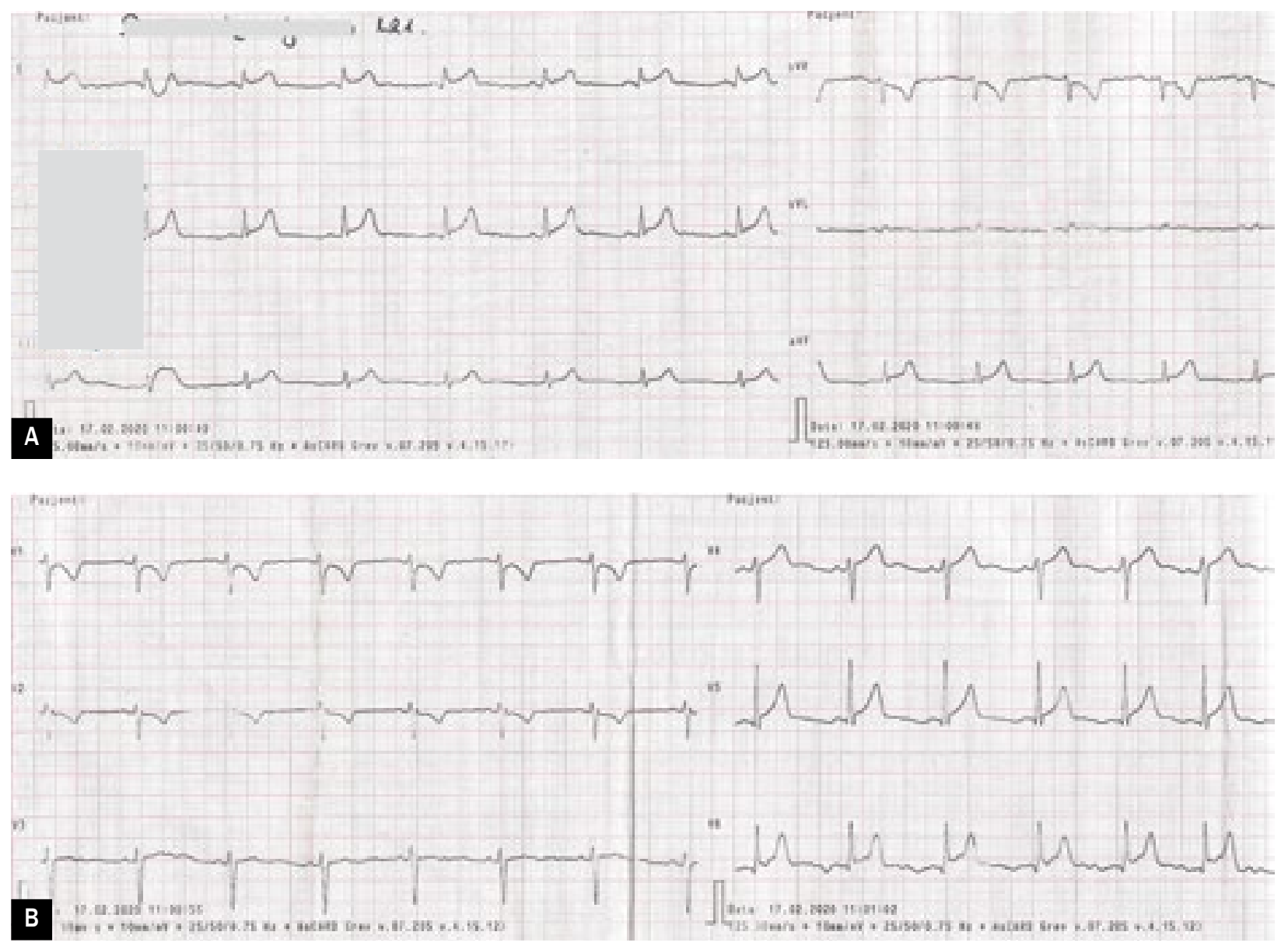

Figure 1. Electrocardiogram (ECG) on admission: regular sinus rhythm with a frequency of approximetaly $65 / \mathrm{min}$, normogram, $P R=120 \mathrm{ms,}$ QRS = 90 ms, QT = 380 ms. Small upward-sloping ST segment elevations in I, II, III, aVF, V3-V6 leads and slight depressions of PR (PQ) segment in these leads

The ECG recorded on admission to the hospital is presented in Figure 1 and the laboratory test results are shown in Table 1. The echocardiography revealed the left ventricular muscle borderline contractility with ejection fraction (EF) of approximately $50 \%$; the left interventricular septum and left ventricular posterior wall were not thickened; the atria and ventricles were not enlarged. Mild-mitral and tricuspid valve regurgitation was observed. Trace amounts of fluid were found in the pericardial sac. Myopericarditis (pericarditis and myocarditis) was diagnosed. The typical treatment of acute pericarditis (the combination of ibuprofen and colchicine) was applied. A gradual improvement in the general condition and alleviation of the reported complaints were observed. Echocardiography performed after five days of hospitalization showed normal heart contractility with EF of $65 \%$, with no fluid in the pericardium, in other cases - a similar pattern to the previous one. The hospitalization lasted eight days. The laboratory test results on the day preceding the discharge from the hospital are shown in Table 2 and the ECG on discharge is presented in Figure 2. It was recommended to limit physical activity for 3 months after discharge.

\section{Discussion}

As mentioned, acute pericarditis can coexist with myocarditis (two possible forms of the disease: myopericarditis or perimyocarditis). Moreover, in the case of acute pericarditis, the pericardial sac fluid does not necessarily have to be present [1]. This was the case here-both above-mentioned anatomical structures were simultaneously infiltrated with a trace amounts of fluid in the pericardial cavity.

The most common cause of pericarditis in industrialized countries is infection with cardiotropic viruses, while in developing countries other infectious agents, such as tuberculosis, are more common. Other causes of pericarditis are autoimmune disorders, metabolic diseases, traumas, cancers, myocardial infarction [1]. The patient was treated as a case with the primary problem in the form of acute pericarditis of most likely viral etiology. Two out of 
Table 1. Laboratory test results on admission to the hospital

\begin{tabular}{|c|c|c|}
\hline Parameter [unit] & Result & Reference range \\
\hline Leucocytes $\left[\times 10^{3} / \mu \mathrm{L}\right]$ & 8.63 & $4.0-10.0$ \\
\hline Hemoglobin [g/dL] & 14.4 & $14.0-18.0$ \\
\hline Hematocrit [\%] & 43.8 & $40.0-54.0$ \\
\hline Thrombocytes $\left[\times 10^{3} / \mu \mathrm{L}\right]$ & 165 & $140-440$ \\
\hline Sodium [mmol/L] & 140 & $136-145$ \\
\hline Potassium [mmol/L] & 4.33 & $3.50-5.10$ \\
\hline Glucose [mg/dL] & 102 & $60-100$ \\
\hline Uric acid $[\mu \mathrm{mol} / \mathrm{L}]$ & 335 & $202-416$ \\
\hline Creatinine $[\mu \mathrm{mol} / \mathrm{L}]$ & 63.7 & $62.0-106.0$ \\
\hline GFR acc. to MDRD & $>90$ & $>90$ \\
\hline Urea [mmol/L] & 5.69 & $2.76-8.07$ \\
\hline APTT [s] & 30.3 & $26.0-36.0$ \\
\hline INR & 0.91 & $0.90-1.20$ \\
\hline $\mathrm{CK}[\mathrm{U} / \mathrm{L}]$ & 902 & $39-308$ \\
\hline CK-MB mass [ng/mL] & 96.08 & $<5.00$ \\
\hline $\begin{array}{l}\text { High-sensitivity } \\
\text { troponin I [ng/L] }\end{array}$ & 20965.35 & $<47.3$ \\
\hline $\mathrm{CRP}[\mathrm{mg} / \mathrm{dL}]$ & 17.50 & $<5.00$ \\
\hline Procalcitonin [ng/mL] & $<0.02$ & $<0.10$ \\
\hline AIAT [U/I] & 24 & $10-50$ \\
\hline AspAT [U/I] & 86 & $10-50$ \\
\hline $\mathrm{TSH}[\mu \mathrm{IU} / \mathrm{mL}]$ & 2.190 & $0.270-4.200$ \\
\hline NT-proBNP [pg/mL] & 471 & $<125$ \\
\hline \multicolumn{3}{|c|}{$\begin{array}{l}\text { GFR - glomerular filtration rate; MDRD - Modification of Diet in Renal Disease; APTT - activated } \\
\text { partial thromboplastin time; INR - international normalized ratio; CK - creatine kinase; } \\
\text { CK-MB - creatine kinase myocardial bound; CRP - C-reactive protein; AIAT - alanine amino- } \\
\text { transferase; AspAT - aspartate aminotransferase; TSH - thyrotropin-stimulating hormone; } \\
\text { NT-proBNP - N-terminal pro-B-type natriuretic peptide }\end{array}$} \\
\hline
\end{tabular}

four main criteria for pericarditis were met, with no evident segment abnormalities of the left ventricular contractility on echocardiography. Standard pharmacological treatment of acute pericarditis was implemented [1, 2], obtaining a very good clinical effect.

In a prospective cohort study, whose results were published in 2008, it was observed that out of 274 patients with acute pericarditis, 40 (14.6\%) suffered from myocarditis as well [3]. Elements of the clinical picture, which were significantly related to the chance of diagnosing myopericarditis, were found on admission to the hospital:

- occurrence of arrhythmia [odds ratio (OR) 17.6, 95\% confidence interval (Cl): 5.7-54.1, $p<0.001)$;

- male sex (OR 6.4, 95\% Cl: 2,3-18.4, p = 0.01);

- age < 40 years (OR 6.1, 95\% Cl: 2.2-16.9, p = 0.01);

- ST-segment elevation (OR 5.4; 95\% Cl: 1.4-20.5, $p=0.013)$;

- recent fever (OR 2.8; 95\% $\mathrm{Cl}: 1.1-7.7 . \mathrm{p}=0.044)$.
Table 2. Laboratory test results the day before discharge

\begin{tabular}{lcc} 
Parameter [unit] & Result & Reference range \\
\hline Leucocytes $\left[\times 10^{3} / \mu \mathrm{L}\right]$ & 7.17 & $4.0-10.0$ \\
Hemoglobin $[\mathrm{g} / \mathrm{dL}$ ] & 15.2 & $14.0-18.0$ \\
Hematocrit [\%] & 46.4 & $40.0-54.0$ \\
Thrombocytes [× $\left.10^{3} / \mu \mathrm{L}\right]$ & 191 & $140-440$ \\
Sodium [mmol/L] & 140 & $136-145$ \\
Potassium [mmol/L] & 4.22 & $3.50-5.10$ \\
Creatinine [ $\mu \mathrm{mol} / \mathrm{L}]$ & 66.0 & $62.0-106.0$ \\
GFR acc. to MDRD & $>90$ & $>90$ \\
Urea [mmol/L] & 6.60 & $2.76-8.07$ \\
CK-MB mass [ng/mL] & 0.90 & $<5.00$ \\
High-sensitivity troponin & 31.16 & $<47.3$ \\
I [ng/L] & & $<5.00$ \\
CRP [mg/dL] & 4.22 & $10-50$ \\
AIAT [U/L] & 31 & $10-50$ \\
AspAT [U/L] & 28 & $<125$ \\
NT-proBNP [pg/mL] & 351 &
\end{tabular}

GFR - glomerular filtration rate; MDRD - Modification of Diet in Renal Disease; CK-MB - creatine kinase myocardial bound; CRP - C-reactive protein; AIAT - alanine aminotransferase; AspAT aspartate aminotransferase; NT-proBNP - N-terminal pro-B-type natriuretic peptide

The clinical diagnosis of myopericarditis in this study was confirmed by i.a. increased levels of myocardial necrosis markers. In the patient described by us, 4 out of 5 above-mentioned elements of the clinical picture, which increase the chance of myopericarditis diagnosis, occurred. In the course of pericarditis, inflammatory markers [C-reactive protein (CRP), erythrocyte sedimentation rate (ESR), leukocyte count) are also elevated [1, 2].

ST segment elevation in many leads with frequently accompanying PR segment depressions is a typical symptom of acute pericarditis. Such changes are found in approximately $60 \%$ of patients. Changes in ECG represent an inflammatory reaction of the inner pericardial layer (epicardium) because the fibrous pericardium does not show any electrical activity. Depending on the degree of myocardial involvement, standard changes may coexist with diffuse changes in the T-wave, including their inversions [1, 4]. In the patient in question, ST segment elevations were present in many leads which did not form any pattern typical of occlusion of one of the epicardial arteries. The enclosed electrocardiogram (Figure 1) is similar to other ones recorded in patients with myopericarditis $[4,5]$. The literature also contains case studies of patients with ECG changes that suggested the occlusion of one of the epicardial arteries, which led to performing coronary angiography that showed no significant lesions in coronary vessels [6-8]. 


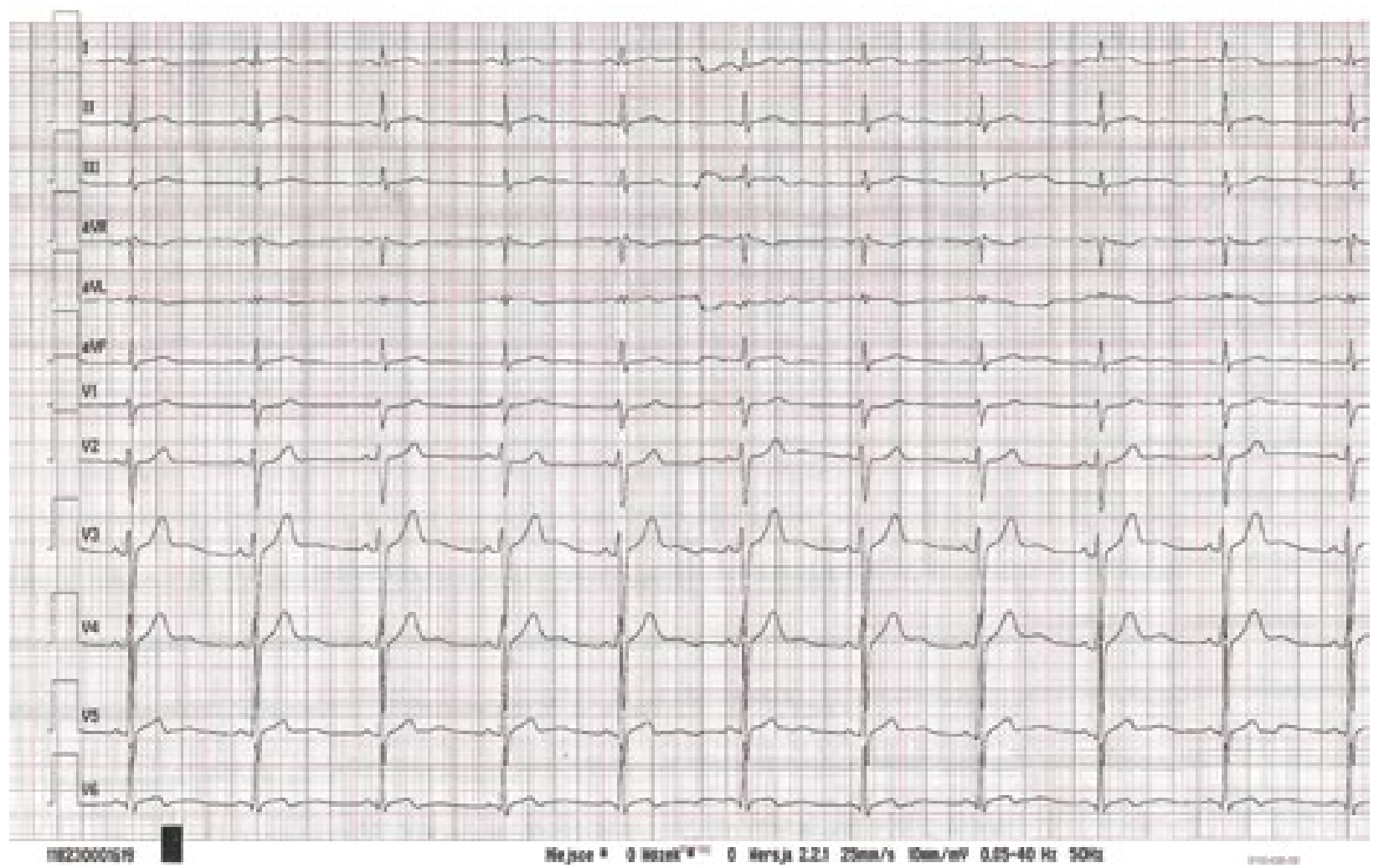

Figure 2. Electrocardiogram (ECG) at discharge: regular sinus rhythm with a frequency of approximately $60 / \mathrm{min}, \mathrm{normogram}, \mathrm{PR}=120 \mathrm{~ms}$, $\mathrm{QRS}=90 \mathrm{~ms}, \mathrm{QT}=400 \mathrm{~ms}$, no significant changes to the ST-T complex

To sum up, in patients with risk factors for atherosclerosis of the blood vessels, pericardial syndromes may be confused with acute coronary syndromes. They should also be differentiated from early repolarization syndromes (similar electrocardiographic pattern). Patients with pericarditis usually report chest pain of pericardial nature. Fever and dyspnea are prevalent. Laboratory tests show elevated inflammatory markers. In patients with myocarditis, myocardial necrosis markers are also elevated. Echocardiography is very helpful in making a proper diagnosis. The patients with dominant signs of pericarditis (myopericarditis) are treated with nonsteroidal anti-inflammatory drugs in high doses, usually in combination with colchicine [1].

\section{Conflict of interest}

The authors declare no conflict of interest.

\section{References}

1. Adler $\mathrm{Y}$, Charron P, Imazio M, et al. ESC Scientific Document Group. 2015 ESC Guidelines for the diagnosis and management of pericardial diseases: The Task Force for the Diagnosis and Management of Pericardial Diseases of the European Society of Cardiology (ESC)
Endorsed by: the European Association for Cardio-Thoracic Surgery (EACTS). Eur Heart J. 2015; 36(42): 2921-2964, doi: 10.1093/eurheartj/ehv318, indexed in Pubmed: 26320112.

2. Imazio M, Cooper LT. Management of myopericarditis. Expert Rev Cardiovasc Ther. 2013; 11(2): 193-201, doi: 10.1586/erc.12.184, indexed in Pubmed: 23405840.

3. Imazio M, Cecchi E, Demichelis B, et al. Myopericarditis versus viral or idiopathic acute pericarditis. Heart. 2008; 94(4): 498-501, doi: 10.1136/hrt.2006.104067, indexed in Pubmed: 17575329.

4. Chan TC, Brady W, Pollack M. Electrocardiographic manifestations: acute myopericarditis. J Emerg Med. 1999; 17(5): 865-872, doi: 10.1016/s0736-4679(99)00097-9.

5. Khan R, Iroka N, Tulpule S, et al. Myopericarditis: a diagnosis of uncertainty. Cardiol Res. 2015; 6(4-5): 332-335, doi: 10.14740/cr428w, indexed in Pubmed: 28197253.

6. Nisbet BC, Breyer M. Acute myopericarditis with focal ECG findings mimicking acute myocardial infarction. J Emerg Med. 2010; 39(5): e153-e158, doi: 10.1016/j.jemermed.2008.01.013, indexed in Pubmed: 18774257.

7. Nozari $\mathrm{Y}$, Tajdini M, Mehrani M, et al. Focal myopericarditis as a rare but important differential diagnosis of myocardial infarction; a case series. Emerg (Tehran). 2016; 4(3): 159-162, indexed in Pubmed: 27299147.

8. Sharif N, Dehghani P. Emergency files: acute pericarditis, myocarditis, and worse! Can Fam Physician. 2013; 59(1): 39-41, indexed in Pubmed: 23341656. 